\title{
NOMADISMO Y ESPÍRITU LIBRE. \\ LA NOCIÓN DE FREISINNIGKEIT EN EL PENSAMIENTO POLÍTICO NIETZSCHEANO
}

\author{
NOMADISM AND FREE SPIRIT. \\ THE NOTION OF FREISINNIGKEIT IN \\ NIETZSCHE'S POLITICAL THINKING
}

\author{
Óscar Quejido Alonso* \\ Universidad Complutense de Madrid
}

\begin{abstract}
Resumen: En diferentes ocasiones a lo largo de su obra, F. Nietzsche utiliza el término Freisinnigkeit para referirse a una cierta «liberalidad de espíritu». Esta noción se relaciona directamente con la de espíritu libre, así como con el planteamiento nietzscheano del nomadismo y, más particularmente, con el de la diáspora judía. En este artículo mostraremos cómo, por medio de estas nociones, Nietzsche genera un espacio para la reflexión política en el que es posible integrar cuestiones tales como su radical crítica al nacionalismo.
\end{abstract}

Palabras Clave: filosofía política, nomadismo, espíritu libre, judíos, nacionalismo.

Авsтract: On different occasions throughout his work, Nietzsche uses the term Freisinnigkeit to refer to a certain "liberality of spirit." This notion is directly related to that of the free spirit, as well as to the Nietzschean approach to nomadism and, more particularly, to that of the Jewish diaspora. In this text we will show how, through these notions, Nietzsche generates a space for political reflection in which issues such as his radical criticism of nationalism can be integrated.

KEYwORDS: political philosophy, nomadism, free spirit, Jews, nationalism.

* Profesor Ayudante Doctor, Departamento de Filosofía y Sociedad, Facultad de Filosofía de la Universidad Complutense de Madrid UCM, Ciudad universitaria s/n, 28040 MadridEspaña, oquejido@ucm.es. 


\section{Introducción}

La filosofía política de Nietzsche, a pesar de las diferentes lecturas realizadas en los últimos años, sigue siendo considerada aún como un terreno pantanoso, especialmente difícil de aislar y de articular dentro de la esfera más general de su pensamiento ${ }^{1}$. Esta dificultad se debe, entre otras cosas, a que lo político -al igual que lo moral-, se conforma en Nietzsche como un medio dentro del cual elaborar su proyecto crítico-antropológico de "elevación del tipo humano". En sentido amplio, la filosofía política nietzscheana reflexiona de manera crítica sobre las condiciones que hasta ahora han impedido esta "elevación del tipo", a la vez que pretende, aunque de forma más difusa, exponer algunas características de un nuevo contexto político-social en el que una verdadera superación de lo humano pueda cobrar forma.

A medida que va quedando atrás la polémica sobre la adscripción política del pensamiento de Nietzsche, se va consolidando la pregunta por la relevancia y la utilidad que algunas de las nociones y planteamientos presentes en su pensamiento puedan tener para la actual reflexión política. De esta manera, desde hace ya algunos años, varios autores han trabajado este tema desde diferentes perspectivas, pero siempre tratando de vincular los principios de la filosofía nietzscheana en general, y de su pensamiento político más particularmente, con elementos de la reflexión política actual ${ }^{2}$. Este tipo de trabajos tratan de profundizar en las

\footnotetext{
1 Para la cuestión de la influencia del pensamiento político de Nietzsche, véase: Lemm, Vanessa (2013). Nietzsche y el pensamiento politico contemporáneo, Santiago de Chile: Fondo de Cultura Económica; Siemens, Herman \& Roodt, Vasti. (Eds.) (2008). Nietzsche, Power and Politics Rethinking. Nietzsche's Legacy for Political Thought, Berlín /N.Y: Walter de Gruyter; Conway, Daniel W. (1997). Nietzsche \& the Political, Berlin/ NY/ London: Routledge; Portales, Gonzalo (2002). Filosofía y catástrofe: Nietzsche y la devastación de la politica, Santiago de Chile: Universidad Arcis; Conill, Jesús (2014). "El sentido de la «Gran política» nietzscheana”, en Guía Comares de Nietzsche, pp. 247-270, Granada: Ed. de Jesús Conill y Diego Sánchez Meca.

2 Además de la conocida repercusión en la obra de Gilles Deleuze y Félix Guattari de cuestiones como las del nomadismo o la geofilosofía, o los estudios biopolíticos iniciados por Michael Foucault, se pueden citar nociones como la de agonismo, que ha sido fundamental en el pensamiento de Herman Siemens o William Connelly, y que, a su vez, sirve de base para la reflexión sobre la noción de «multitud», que tanta importancia ha tenido en autores como Toni Negri y Michael Hard. Podemos también mencionar los planteamientos de Judith Butler sobre la performatividad, fundamentales para el desarrollo de los "grupos queer", y que pueden vincularse al pensamiento nietzscheano a partir de la des-esencialización y el constructivismo implícitos en éste.
} 
condiciones que harían posible la creación de un nuevo contexto político realmente plural, generado a partir del desarrollo del proyecto crítico-antropológico de Nietzsche. Un nuevo espacio de reflexión política que no elimina, sin embargo, los mecanismos de identificación cultural, sino que reconsidera su importancia real en la construcción de una identidad, repensando, con ello, los dispositivos que históricamente los han generado.

El concepto de diáspora y el nomadismo que ésta conlleva han cobrado en los últimos ańos, tanto en las ciencias sociales como en la filosofía política, especial relevancia cuando se trata de pensar procesos como los de la globalización, el multiculturalismo o la conformación de identidades transculturales. En este sentido podemos preguntarnos: ¿qué puede aportar la cuestión de la diáspora judía, tal y como la pensó Nietzsche, a la discusión política actual sobre el escenario pluricultural de las democracias modernas? Es decir, si entendemos la diáspora judía como un caso particular de una categoría más general, como es la de las actuales comunidades deslocalizadas, entonces ¿qué caracteres y consecuencias podemos extraer de ésta que nos ayuden a comprender dichos fenómenos en la conformación política multicultural y globalizada actual?

En este sentido, tal y como acabamos de señalar, la caracterización nietzscheana de la diáspora judía destacaría, por una parte, por la manera en que ésta se articula y sustenta sobre algunas nociones básicas de su pensamiento y, por otra parte, porque muestra qué representa ésta, más particularmente, dentro de su reflexión política, es decir, por su importancia a la hora de generar un nuevo espacio para lo político como el que se requiere para la elevación del tipo humano.

\section{La noción de «liberalidad espiritual»[Freisinnigkeit] en el pensamiento nietzscheano.}

Los primeros usos, en la obra juvenil de Nietzsche, de la noción de «liberalidad espiritual» [Freisinnigkeit] se remontan a un apunte póstumo de 1875, y se circunscriben al ámbito del agonismo griego como dispositivo de control de las pulsiones, en oposición a la "moral" y, más claramente, al Estado como estructura política: 
[...] El placer de la embriaguez, el placer de la astucia, de la venganza, la envidia, el insulto, la obscenidad -todo esto fue reconocido por los griegos como algo humano, y por ello debidamente incorporado al edificio de la sociedad y las costumbres. La sabiduría de sus instituciones reside en la ausencia de separación entre bueno y malo, blanco y negro. La naturaleza, tal como ésta se muestra, no fue negada, sino sólo debidamente incorporada, circunscrita a determinados cultos y días. Esta es la raíz de toda la liberalidad de espíritu [Freisinnigkeit] de la Antigüedad; para las fuerzas naturales se buscaba una descarga mesurada, en lugar de una aniquilación y negación de las mismas. El sistema conjunto del nuevo orden es, por tanto, el Estado ${ }^{3}$.

Estas anotaciones acabarían formando finalmente parte de la segunda parte de Humano, demasiado humano. En Opiniones y sentencias varias Nietzsche retoma el tema de los griegos de la siguiente manera ${ }^{4}$ :

No negaban el instinto natural que se expresa en las malas cualidades, sino que lo integraban y lo limitaban a determinados cultos y días, después de haber ideado las suficientes medidas precautorias para poder dar a esas aguas bravas un curso lo más inofensivo posible. Esta es la raíz de toda la liberalidad moralista [moralistischen Freisinnigkeit] de la antigüedad. A lo malo y desasosegante, a los restos de animalidad, así como a lo bárbaro, prehelénico y asiático que todavía vivía en el fondo de la esencia griega, se le permitía una descarga moderada, sin aspirar a su completa aniquilación. El Estado, que no estaba construido sobre individuos o sobre castas singulares, sino sobre las cualidades humanas habituales, abarcaba todo el sistema de tales ordenanzas. En su armazón muestran los griegos ese admirable sentido para lo típico-fáctico que más tarde les capacitó para convertirse en naturalistas, historiadores, geógrafos y filósofos. No era una ley moral limitada, sacerdotal o de casta, la que tenía que decidir en la constitución del Estado

3 NIETZSCHE, Friedrich (2008) Fragmentos póstumos. vol. III. 5 [146]. Ed. dirigida por Diego Sánchez Meca, Madrid: Tecnos (A partir de ahora, FP, seguido del volumen).

4 La primera parte del póstumo aparece en $H D H, I, 62$ en referencia a Homero y el carácter panhelénico. 
y del culto del Estado, sino las más comprehensiva consideración respecto a la realidad de todo lo humano5.

Esta primera acepción de Freisinnigkeit aparece en relación directa con la estructura sociopolítica del mundo griego. Tal y como señala el apunte póstumo, la Freisinnigkeit, la liberalidad de espíritu, se reflejaría en "la sabiduría de sus instituciones", y residiría en "la ausencia de separación entre bueno y malo" . A su vez, unas líneas más abajo, Nietzsche relaciona esta cuestión con cierto "sentido para lo real", o cierto "gusto para las realidades particulares de toda clase", propio del carácter esencial de la poesía y los poetas. Este "sentido para la realidad" en tanto que plural, diversa, -que es el origen y el carácter de la "liberalidad" del mundo griego pre-platónico-, además, comprende el mal (la apariencia) como un componente fundamental de dicha realidad y no pretende en ningún caso su eliminación, -que supondría, en último término, la eliminación de la realidad-, sino que únicamente pretende su adecuada administración: "matizarlo de modo que no acabe con todo lo demás"', en la idea de que ninguna fuerza puede pretender la eliminación radical de sus opuestos, sino que debe buscar su control y dominio. Nietzsche nos presenta esta manera de pensar, propia de poetas, como análoga a la de "los fundadores griegos de Estados".

Fue este modo de afrontar la realidad el que guió en último término la organización del Estado griego, que asumía también como propias de la naturaleza humana las cualidades denominadas malas, gestionándolas y administrándolas mediante determinadas prácticas sociales por medio de sus instituciones. Por tanto, para Nietzsche, en Grecia la entera condición humana "no fue negada, sino sólo debidamente incorporada" .

5 NIETZSCHE, Friedrich. Obras completas Volumen III: Obras de madurez I (A partir de ahora, $O C$, seguido del volumen correspondiente y de la obra); Humano, demasiado humano, II, 220 (A partir de ahora, $H D H$ ).

6 Esta "ausencia de separación" tiene el mismo sentido que la crítica que hace Nietzsche a los errores de los filósofos cuando en Más allá del bien y del mal, 2, éste se refiere al "prejuicio de las antítesis".

7 FP, vol. II, 5 [146].

$8 H D H$, II, 220.

9 FP, vol. II, 5 [146]. 
De esta manera, la noción de la liberalidad de espíritu, la Freisinnigkeit, tal y como aparece en estos textos, es caracterizada como una noción práctica-Nietzsche añade la palabra "moral" para referirse a ella en el aforismo 220 de Opiniones $y$ sentencias varias-, pero vinculada directamente, por una parte, a una propuesta teórico-interpretativa de la realidad que pretende ser crítica o sustitutiva de la propuesta metafísica tradicional y, por otra, a una alternativa de orden político. Se puede decir que se trata de un concepto puente entre la crítica a la metafísica llevada a cabo por Nietzsche, y su crítica de la cultura y el orden social.

\section{Freisinnigkeit y espíritu libre}

En el aforismo 44 de Más allá del bien y del mal10, así como en la correspondiente anotación en sus cuadernos, Nietzsche discute de manera crítica las diferencias entre las figuras del espíritu libre y el librepensador.

Lo que me separa de ellos son las estimaciones de valor: porque todas ellas forman parte del movimiento democrático y quieren derechos iguales para todos, ven en las formas de la antigua sociedad las causas de las deficiencias y degeneraciones humanas, se entusiasman con la quiebra de estas formas: y entretanto les parece que lo más humano que pueden hacer es procurar a todos los hombres su nivel de liberalidad espiritual [Freisinnigkeit]. En suma, forman parte de los «niveladores», de aquella especie de hombres que me repugna en cualquier sentido al gusto y todavía más a la razón. Quiero, incluso en las cosas del espíritu, guerra y contraposiciones; y más guerra que nunca, más "contraposiciones» que nunca ${ }^{11}$.

Si bien es cierto que en el aforismo 44 no se conservó directamente el término Freisinnigkeit, sí que se mantiene en él el sentido dado en la anotación. En particular, cabe destacar que el problema de los librepensadores no es tanto, a juicio de Nietzsche, que traten de traspasar a "todos los hombres su nivel de liberalidad espiritual [Freisinnigkeit]", sino el modo de hacerlo, nivelador y democrático; dicho modo considera la liberalidad de espíritu como un derecho,

10 OC, IV; Más allá del bien y del mal, 44 (A partir de ahora, MBM).

11 FP, vol. III, 36 [17]. 
olvidando que son las condiciones adversas las que permiten la elevación del tipo. La verdadera "amplitud de espíritu" de los verdaderos espíritus libres se caracteriza por no aceptar "que las formas de la vieja sociedad existente hasta hoy son más o menos la causa de toda miseria y fracaso humanos", o lo que es lo mismo, por no querer "derechos iguales para todos" ni tener "compasión con todo lo que sufre" ${ }^{12}$. Esta falta de igualdad y de compasión es, precisamente, la que ha hecho crecer más vigorosamente a la "planta hombre".

Por tanto, Nietzsche reivindica como notas esenciales de la Freisinnigkeit, de la liberalidad de espíritu, tanto la "jerarquía" entre los hombres, como la permanente superación de "prejuicios" que conlleva el quedarse fijo en una determinada posición intelectual. De esta manera, profundizar en la noción de Freisinnigkeit supone revisar estas diferencias específicas. Freisinnigkeit y nomadismo quedan así unidos en el planteamiento nietzscheano.

Hemos tenido nuestra casa, o al menos nuestra hospedería, en muchos países del espíritu; hemos escapado una y otra vez de los enmohecidos y agradables rincones en que el amor y el odio preconcebidos, la juventud, la ascendencia, el azar de hombres y libros, e incluso las fatigas de la peregrinación parecían confinarnos ${ }^{13}$.

Como veremos a continuación, Nietzsche encuentra estas dos condiciones en la diáspora judía. En varios lugares de su obra destacó el papel de los judíos en el futuro político de Europa, vinculándolos, como ahora veremos, a esta liberalidad de espíritu.

\section{Nietzsche y los judíos. La Freisinnigkeit y su importancia política}

Más allá de su juvenil antisemitismo, vinculado a su relación con Wagner, y de las críticas que posteriormente dirigirá al entorno de los "sacerdotes judíos" $y$ a la forma en que estos han expresado su fe, Nietzsche se muestra interesado

\section{$M B M, 44$}

13 Ibid. 
por la "diáspora judía" en términos políticos. Las diferentes maneras en las que se refiere a los judíos en sus obras han sido analizadas por diferentes autores, mostrándose que la relación entre la cuestión judía y la «filosofía» de Nietzsche puede ser tratada dejando a un lado los diferentes usos ideológicos que se hayan podido realizar.

Por su parte, Yovel ha afirmado que, para superar la aparente "ambivalencia" nietzscheana con respecto a la cuestión judía (a su posible antisemitismo), hay que observar que Nietzsche distingue tres momentos dentro de la experiencia hebrea, manifestándose siempre favorable respecto al judaísmo bíblico y al desarrollado en la denominada "diáspora judía», al mismo tiempo que muy crítico con el judaísmo sacerdotal por medio del que "la revolución de la «moral de los esclavos» tomó forma, la más importante desnaturalización e inversión de los valores que dio paso al cristianismo" ${ }^{14}$.

Sin embargo, establecer las relaciones internas entre estos tres tipos de judaísmo propuestos por Yovel a lo largo de la obra de Nietzsche no es sencillo, y parece que esta afirmación debe ser matizada si queremos entender en toda su profundidad el papel que desempeńa la diáspora judía y las nociones que se articulan en torno a ella en el pensamiento nietzscheano.

Aunque, en cierto sentido, la diáspora judía puede ser considerada como una forma de resistencia contra el poder establecido, ésta no se ha caracterizado históricamente por ser un elemento especialmente crítico con la autoridad. Nietzsche, sin embargo, va a desvelar el papel fundamental de la diáspora; primero, en la conformación y desarrollo del judaísmo sacerdotal y, segundo, al convertirse en referencia directa del cristianismo por medio de la figura de Pablo. No obstante, Nietzsche considera que la manera en que se han desarrollado ambos fenómenos culturales supone, de hecho, una destrucción de las condiciones que han hecho,

14 YOVEL, Yimiryahu (1997). "Sublimity and Ressentiment: Hegel, Nietzsche, and the Jews», en Jewish social studies. Indiana: Indiana University Press; (1997) Nietzsche and jewish culture. NY- London: Routledge, pág. 14. Ed. de Jacob Golomb. 
a su juicio, de los judíos “[...] sin ninguna duda, la raza más fuerte, más tenaz y más pura que vive ahora en Europa" ${ }^{\prime 15}$.

De esta manera, la figura de la diáspora judía gana en la filosofía política de Nietzsche una potencia crítica con respecto al desarrollo de la cultura occidental, ya que ve en ella la conservación de ciertos caracteres que va a considerar decisivos para el futuro político de Europa. ${ }^{16}$

Ya en $H D H$, Nietzsche anticipa un futuro político y social para Europa en el que según escribe:

El rápido cambio de lugar y de paisaje, la actual vida nómada de los que no poseen tierras $[\ldots]$ comportan necesariamente un debilitamiento $y$, por último, una destrucción de las naciones, al menos de las europeas: de modo que de ellas debe nacer, como consecuencia de los continuos cruces, una raza mixta la del hombre europeo ${ }^{17}$.

Es en este contexto sociopolítico en el que la diáspora judía tiene interés para Nietzsche y en el que, como veremos, a su vez, su reflexión sobre ella puede tener interés para la filosofía política actual: «Un pensador que tenga sobre su conciencia el futuro de Europa -escribe Nietzsche- contará, en todos los proyectos que trace en su interior sobre ese futuro, con los judíos» ${ }^{18}$.

\footnotetext{
15 MBM, 251.

16 FREY, Herbert (2005). "Politeísmo versus monoteísmo: el desarrollo a la crítica a la religión cristiana", en Revista mexicana de sociología, 67, n. 3, pp. 513-541, México, D.F., julio-septiembre 2005. Muestra cómo el punto de conexión entre la religión y la política lo establece Nietzsche a partir de la noción de "resentimiento".

$17 \mathrm{HDH}, \mathrm{I}, 475$.

$18 M B M, 251$.
}

ÉNDOXA: Series Filosóficas, n. 43, 2017, pp. 155 - 169. UNED, Madrid 
El aforismo 205 de Aurora relata las terribles condiciones en las que han vivido los judíos y cómo éstas han supuesto "una escuela de dieciocho siglos", cuyas consecuencias permiten afirmar que:

[...] entre los actuales judíos, los recursos anímicos y espirituales son extraordinarios. [...]. Cualquier judío encuentra en la historia de su padre y de su abuelo un manantial de ejemplos de razonamiento frío y de perseverancia en situaciones terribles, del más ingenioso aprovechamiento de la desgracia y la casualidad ${ }^{19}$.

Estos "recursos del alma”, este carácter distintivo de la "inteligencia" de los judíos a los que se refiere Nietzsche han sido ejemplos de prudencia y perseverancia para aprovechar ingeniosamente la desgracia, para convertir, de esta manera, la miseria en grandeza, haciendo de la necesidad, virtud. Los judíos han incorporado estas experiencias a su vida, aumentado así su capacidad de adaptabilidad en un entorno cambiante como el que se ha visto obligada a vivir la diáspora. Pero como no hay que olvidar que la capacidad de adaptación que han ido adquiriendo a lo largo de los siglos tenía como fin último la conservación de la comunidad en un entorno cambiante, la adaptabilidad y la flexibilidad deben ser entendidas como medios para la conservación. No obstante, la conservación no puede ser considerada tampoco como un fin en sí misma, sino únicamente como la consecuencia derivada de la fortaleza del organismo, de su capacidad para crecer, en el doble sentido implícito en la noción de voluntad de poder, tal y como lo hemos presentado. En un apunte de 1888 Nietzsche escribe:

Los judíos son, en una Europa insegura, la raza más fuerte: pues, por lo prolongado de su evolución, son superiores al resto. Su organización presupone un devenir más rico, una carrera más peligrosa, un número mayor de etapas que aquéllos que todos los otros pueblos pueden reivindicar. Y esto es prácticamente la fórmula de la superioridad. - Una raza, como cualquier otra formación orgánica, no puede sino crecer $o$ perecer; no hay ningún momento de reposo. Una raza que no haya perecido es una raza que no ha cesado de crecer. Crecer significa ir perfeccionándose. La duración de la

19 OC, III, Aurora (a partir de ahora, M), 205. 
existencia de una raza decide con necesidad sobre el nivel de su evolución: la más antigua tiene que ser la más elevada ${ }^{20}$.

Todos los mecanismos que garantizan la identidad cultural de una comunidad suelen ser entendidos como imposiciones a los individuos con el fin de conservar dicha organización. Por el contrario, para Nietzsche la cultura en tanto que define una unidad y sirve de referente para la identidad cultural de los individuos, es vista como el lugar donde "almacenar" y generar un superávit de energía, de fuerza, que permita a la comunidad ponerse en juego (y no únicamente conservarse) para, de esta manera, o bien crecer, o bien perecer. Los mecanismos de identificación cultural en Nietzsche no son válidos si no son vistos bajo la perspectiva de la guerra, del enfrentamiento: si conservamos algo, lo hacemos siempre para poder arriesgarlo. El discurso moderno que ha privilegiado la identidad no es eliminado por Nietzsche, pero sí es desplazado a un lugar secundario. La diáspora judía en su existencia nómada ha arriesgado en cada movimiento, en cada cambio, su identidad; su "fortaleza de espíritu» se debe a que, más que nadie, ha sabido conservar y acumular lo conseguido; pero la identidad es en este sentido secundaria, una consecuencia de la conservación, no entendida ésta última como un fin en sí mismo, sino siempre como un compromiso de mayores garantías de éxito en una nueva guerra.

Nietzsche caracteriza a la comunidad judía de la diáspora como una herramienta crítica del sistema político, social y moral europeos. El éxito de los judíos se encuentra en "ciertas virtudes que hoy a la gente le gusta tildar de vicios" 21 A lo largo de la historia "se les ha querido hacer despreciables, por lo que se les ha tratado con desprecio durante cerca de dos mil ańos"22 y, sin embargo, la sobreestimación propia del fuerte les es propia: los judíos "han sabido crearse un sentimiento de poder y de venganza eterna" necesario para la propia estimación de sí mismos; es decir, la diáspora judía ha conservado en su interior uno de los elementos más polémicos de la filosofía nietzscheana: la jerarquía.

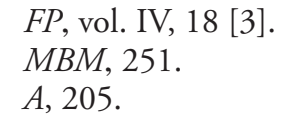


Si bien es cierto que los judíos han cedido su posición dominante dentro de la jerarquía del orden político europeo y que han permanecido en una posición de subordinación con respecto a su Dios en el plano religioso, sin embargo, no es menos cierto que se consideran a sí mismos el pueblo elegido por Dios. En este sentido, mantienen una posición superior frente a todos los demás pueblos. Todo el imaginario de los judíos se ha desplazado hacia su estructura organizativa: «El modo que tienen de honrar a sus padres y a sus hijos, la sensatez de sus matrimonios y costumbres conyugales los distinguen de todos los europeos». ${ }^{23}$

Sobre estas maneras y costumbres de las que, como indicamos más arriba, Pablo va a tomar su aportación para la construcción del cristianismo, Nietzsche escribe:

La realidad sobre la que pudo construirse el cristianismo fue la pequeña familia judía de la diáspora, con su calidez y su ternura, con su disposición, inaudita [...] a ayudar, a solidarizarse unos con otros, con su orgullo de «elegidos» oculto y disfrazado de humildad, con su más íntimo decir no sin envidia a todo lo que está por encima y tiene para sí esplendor y poder. Haber reconocido esto como poder, haber reconocido que este estado anímico era comunicable, seductor, contagioso también para los paganos - es el genio de Pablo ${ }^{24}$.

Ahora bien, el elemento que va a diferenciar, a juicio de Nietzsche, el desarrollo histórico del cristianismo y, como veremos a continuación, del nacionalismo -en un contexto político-, aparece en este texto bajo la expresión "decir no sin envidia" que caracteriza a la existencia del judío. Del mismo modo y con la misma intención en Aurora, escribe Nietzsche:

Con todo, su venganza no ha ido demasiado lejos, pues poseen esa liberalidad intelectual [Freisinnigkeit] y de alma, en la que se educa el hombre que cambia frecuentemente de lugar y de clima y tiene contacto con

23 Ibid.

24 FP, vol. IV, 10 [181] (278). 
las costumbres de vecinos y opresores; han llegado a alcanzar una enorme experiencia en lo que a relaciones humanas se refiere, y hasta en sus pasiones aprovechan la prudencia proporcionada por esta experiencia; están tan seguros de su flexibilidad intelectual y de su habilidad que nunca, ni en los momentos más difíciles, tienen necesidad de ganarse el pan con el esfuerzo físico como, por ejemplo, en trabajos rudos como mozo de cuerda o sega$\operatorname{dor}^{25}$.

Esta noción de Freisinnigkeit es la que mejor caracteriza, por tanto, a esa inteligencia judía. Una flexibilidad intelectual, propia de aquellos hombres que "cambian frecuentemente de lugar y de clima" y que tienen contacto con las costumbres de "vecinos y opresores". Es en este carácter flexible que, al mismo tiempo, es capaz de conservar lo conseguido, donde realmente podemos encontrar la fuerza de la comunidad judía, y del que deriva su identidad. Este es el verdadero antídoto contra el nacionalismo.

Realmente, para Nietzsche, la diáspora supone un modelo de estructuración social y cultural que adquiere sentido pleno bajo una concepción de lo político opuesta al modelo nacionalista tradicional en el que se han forjado los Estadosnación. A diferencia del modelo nacionalista en el que la identidad se relaciona con la esencia, como hemos visto, la propuesta nietzscheana aparece como expresión del crecimiento, en el contexto de la hipótesis de la voluntad de poder. En el ámbito de la política, esto supone una superación de la política tradicional de las naciones (de los Estados-nación), caracterizada por su vinculación al territorio y, por tanto, esencialista y fija. Así, escribe Nietzsche:

A los judíos su inteligencia les impide volverse locos a nuestra manera: por ejemplo, nacionalistas. Parece que se hubieran vacunado demasiado bien en otro tiempo, incluso de manera un poco sangrienta, y esto, entre todas las naciones [...] Hoy son incluso un antídoto contra esta última enfermedad de la razón europea ${ }^{26}$.

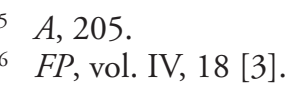


La respuesta nacionalista -que Nietzsche va a denunciar, ante los inevitables cambios que conducen hacia una Europa transnacional-, suele presentarse en la forma de los "anti", incluido el antisemitismo. Esos, escribe Nietzsche,

[...] pequeños ataques de estupidizamiento: por ejemplo, entre los alemanes de hoy, unas veces la estupidez antifrancesa, otras la antijudía, otras la antipolaca, otras la cristiano-romántica.[...etc] Y, ante todo, cerrar las puertas $[\ldots]$ eso es lo que ordena el instinto de un pueblo cuya naturaleza es todavía débil e indeterminada, de modo que con facilidad se la podría hacer desaparecer, con facilidad podría ser borrada por una raza más fuerte ${ }^{27}$.

Esta forma que moldea la política en torno a los "anti” es para Nietzsche la expresión de la debilidad de un pueblo que no es capaz de digerir la potencia cultural de otra forma de pensamiento, la de aquellos que entienden la identidad cultural en términos de una esencia nacional, fija e inmutable. A lo que habría que añadir la idea que hemos mencionado más arriba, de que los cambios en Europa se suceden con demasiada rapidez, impidiendo cualquier posibilidad de acumulación que garantice una adecuada autoconservación de los rasgos culturales.

\section{Conclusiones}

En conclusión, podemos afirmar que la propuesta nietzscheana sobre el contexto de lo político, en la que el significado asignado a la diáspora judía desempeña un papel fundamental, tiene sentido principalmente dentro de una determinada manera de entender el contexto transnacional o postnacional. A juicio de Nietzsche, el proceso de surgimiento tanto del cristianismo como del judaísmo sacerdotal, así como el del contexto que permite el desarrollo de una política que culmina con el nacionalismo, -en la medida en que podemos relacionarlos con la diáspora judía-, consiste en un proceso de "desnaturalización". Además de las cuestiones que acabamos de señalar sobre la identidad cultural o el resentimiento, vinculadas al análisis nietzscheano de este proceso de desnaturalización,

27 MBM, 251. 
irán apareciendo en su pensamiento otras nociones y desarrollos fundamentales que, desde un punto de vista crítico, se muestran fundamentales para corrientes actuales de pensamiento como la biopolítica o los estudios postcoloniales o los culturales en general.

\section{Bibliografía}

Frey, Herbert (2005). "Politeísmo versus monoteísmo: el desarrollo a la crítica a la religión cristiana”. Revista mexicana de sociologia, 67, n. 3, pp. 513-541.

Lemm, Vanessa (2013). Nietzsche y el pensamiento politico contemporáneo, Santiago de Chile: Fondo de Cultura Económica.

Nietzsche, Friedrich. (2008). Fragmentos póstumos. Vol. III. Ed. dirigida por D. Sánchez Meca, Madrid: Tecnos.

- (2014). Obras completas. Vol. III: Obras de madurez I. Ed. dirigida por D. Sánchez Meca, Madrid: Tecnos.

Portales, Gonzalo (2002). Filosofía y catástrofe: Nietzsche y la devastación de la politica, Santiago de Chile: Universidad Arcis.

Siemens, Herman \& V. Roodt, Vasti (Eds.) (2008). Nietzsche, Power and Politics Rethinking. Nietzsche's Legacy for Political Thought, Berlín/N.Y: Walter de Gruyter.

Yovel, YirmiYahu (1997). "Sublimity and Ressentiment: Hegel, Nietzsche, and the Jews". Jewish social studies. Indiana: Indiana University Press.

- (1997). Nietzsche and jewish culture. NY/London: Routledge, Ed. de Jacob Golomb.

Recibido: 5/06/2018

Aceptado: 25/01/2019

Este trabajo se encuentra bajo una licencia de Creative Commons ReconocimientoNoComercial-SinObraDerivada 4.0

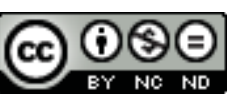

ÉNDOXA: Series Filosóficas, n. ${ }^{\circ}$ 43, 2017, pp. 155 - 169. UNED, Madrid 
